\title{
Evaluation of micro-structural damage caused by needle penetration testing
}

\author{
D. J. M. Ngan-Tillard · H. K. Engin • \\ W. Verwaal $\cdot$ A. Mulder $\cdot$ R. Ulusay $\cdot$ \\ Z. A. Erguler
}

Received: 25 September 2011/Accepted: 12 March 2012/Published online: 24 April 2012

(C) The Author(s) 2012. This article is published with open access at Springerlink.com

\begin{abstract}
The needle penetrometer (NP) is a nondestructive, cheap and simple device which can be used indirectly to obtain the uniaxial compressive strength of extremely weak rocks. It requires little sample preparation and can be used in the field and laboratory and applied in natural and man-made structures where sampling is not allowed. The microstructural damage created by the needle, its shape and size, have been assessed using four rock types (marl, mudstone and tuff from Turkey and calcarenite from the Netherlands) and two types of needle. During needle penetration, very high compressive and shear stresses are developed in advance of the needle and normal to the shaft. In all the tested rocks, densification occurred in a zone some 0.4 and $1 \mathrm{~mm}$ ahead of the Maruto and Eijkelkamp needles respectively. The grains are crushed and compacted in a zone which appears like an extension of the needle tip (Eijkelkamp needle). As damage is local, the NP test is said to be non-destructive. The $\mathrm{NP}$ results in coarse grained rocks are far more variable than in fine grained rocks. The damage caused by a needle decreases with a decrease in the diameter of the needle and an increase in the slenderness of the needle.
\end{abstract}

D. J. M. Ngan-Tillard ( $₫) \cdot$ H. K. Engin · W. Verwaal ·

A. Mulder

Department of Geoscience and Engineering, Geo-engineering Section, Delft University of Technology, Delft, The Netherlands e-mail: D.J.M.Ngan-Tillard@tudelft.nl

R. Ulusay

Department of Geological Engineering, Hacettepe University, Beytepe, 06800 Ankara, Turkey

Z. A. Erguler

Department of Geological Engineering, Dumlupinar University, 43100 Kutahya, Turkey
Keywords Needle penetrometer - Needle penetration resistance $\cdot$ Microstructural damage · Tuff - Calcarenite . Mudstone $\cdot$ Marl

Résumé Le pénétromètre à aiguille est un matériel simple et peu coûteux, non destructif, qui peut être utilisé pour obtenir indirectement la résistance à la compression simple de roches de très faible résistance. Il demande peu de préparation d'échantillon et peut être utilisé sur le terrain et au laboratoire. Il peut être utilisé pour des structures naturelles ou artificielles où l'échantillonnage n'est pas autorisé. Les dommages microstructuraux créés par l'aiguille, considérant sa forme et sa taille, ont été évalués à partir de quatre types de roches (une marne, une roche argileuse et un tuf de Turquie et une calcarénite des Pays-Bas) et deux types d'aiguille. Pendant la pénétration de l'aiguille, des contraintes de compression et de cisaillement très fortes apparaissent en avant de l'aiguille et perpendiculairement à l'axe de l'aiguille. Pour toutes les roches testées, la densification apparait dans une zone de $0,4 \mathrm{~mm}$ et de $1 \mathrm{~mm}$ en avant, respectivement avec l'aiguille de Maruto et l'aiguille d'Eijkelkamp. Les grains sont alors écrasés et compactés dans une zone qui apparaît comme un prolongement de l'extrémité de l'aiguille (aiguille d'Eijkelkamp). Le test est dit non destructif car le dommage est local. Les résultats au pénétromètre à aiguille dans des roches à gros grains sont beaucoup plus variables que dans les roches à grains fins. Les dommages causés par une aiguille décroissent avec une diminution du diamètre de l'aiguille et une augmentation de l'élancement de l'aiguille.

Mots clés Pénétromètre à aiguille · Résistance à la pénétration d'une aiguille $\cdot$ Dommage microstructural . Tuf C Calcarénite $\cdot$ Roche argileuse $\cdot$ Marne 


\section{Introduction}

One of the mechanical properties of rocks widely used in rock mass classification schemes and rock engineering design is the uniaxial compressive strength (UCS). However, the UCS test, particularly on weak and clay-bearing rocks, is time consuming and challenging due to sample preparation as well as experimental procedures. Therefore, cheap and portable test equipment and associated strength indices for indirect estimation of the UCS of rock materials have become popular. One such technique is the needle penetrometer (NP), a non-destructive test that has been designed to provide quick and cheap strength estimation for weak rocks, with minimal preparation of the material tested. It also has the advantage that it can be used at natural and man-made historical and ancient sites where sampling is not allowed.

The NP device consists of pushing a needle into a rock and measuring the resistance to penetration (needle penetration resistance, NPR) as a function of the penetration depth. It can be used, in any direction, both in the field on outcropping rocks or loose blocks and in the laboratory on borehole cores. Although to date the NP has mainly been used in Japan, more recently it has also been used in Turkey and the Netherlands but to date it is not included in
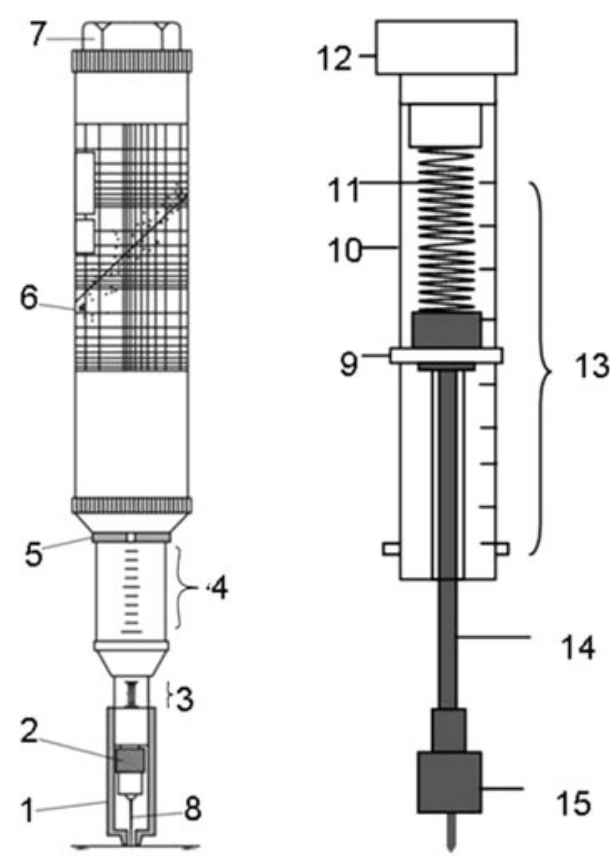

Fig. 1 Maruto (left) and modified Eijkelkamp (right) NP and their parts from Ngan-Tillard et al. (2011). 1 presser, 2 chuck, 3 penetration scale, 4 load scale, 5 load indication ring, 6 UCS-NPR correlation chart given by the manufacturer, 7 removable cap, 8 penetration needle produced according to the Japan Civil Engineering Society's guideline, 9 indicator ring, 10 penetrometer tube, 11 spring, 12 end cap, 13 scale, 14 extension rod, and 15 needle block any Standards or Suggested Methods. According to the manufacturer of the NP (Maruto Co. Ltd. 2006), it is best suited for field use on weak to very weak rocks. Rock type, notably mineralogy and grain size are likely to affect NP readings and spread. For different rock types, different types of failure mechanisms are expected to take place in the direct vicinity of the needle during needle penetration. As damage is local, the test is said to be non-destructive.

Although some studies on the estimation of UCS from NPR have been carried out, with the exception of a study on one rock type (Ngan-Tillard et al. 2011), the micro-structural damage caused by NP has not been investigated in detail. This paper discusses the microstructural damage caused by two types of needle penetrometers developed in Japan and the Netherlands: the Maruto and the modified Eijkelkamp penetrometers, respectively (Fig. 1). The influence of the needle shape and size on the failure pattern is highlighted. For this purpose, tests were carried out on coarse and fine grained rocks of different mineralogy, such as marl, mudstone, tuff and calcarenite, collected from Turkey and the Netherlands. Various specialist equipment [medical CT-scanners, a micro-CT scanner, a light microscope and an environmental scanning electronic microscope (ESEM)] was used to facilitate a multi-scale damage study.

\section{Needle penetrometers used in the study}

The most common NP model is the SH-70 penetrometer manufactured by Maruto Corporation Ltd., Tokyo, Japan (http://www.maruto-group.co.jp/products/rock_asphalt/SH70.htm; Maruto Co. Ltd. 2006; see Fig. 1, left). The test equipment and procedure have been presented in detail by Erguler and Ulusay (2007) and Ulusay and Erguler (2011). The Maruto NP was designed to be used for measuring the penetration of weak rocks in accordance with the penetration testing method specified in the Japan Society of Civil Engineers's Guideline (1991). The Japanese Geotechnical Society (2004) suggested the NP testing method is applicable to rocks having a UCS $<10 \mathrm{MPa}$. Okada et al. (1985), Yamaguchi et al. (1997), Takahashi et al. (1998) and Naoto et al. (2004) recommended empirical relationships between UCS and NPR using mudstone, siltstone, sandstone, marl, tuff, greywacke and clay samples. Hachinohe et al. (1999) tried to identify weathered and unweathered parts of mudstones and sandstones in Japan based on the variation in NPR with penetration depth.

More recently, Erguler and Ulusay (2007, 2009) carried out a series of NP and UCS tests on weak clay-bearing rocks collected from Turkey using a Maruto NP and recommended a relationship between UCS and NPR with a high coefficient of correlation. These investigators (Ulusay and Erguler 2011) also combined all available data on 
UCS-NPR both from Japan and Turkey and having carried out additional tests, recommended a more general NPRUCS relationship. In addition, they showed that the rate of penetration had no effect on the test result, and discussed the possible uses of NP in rock engineering.

Aydan et al. (2008) developed a penetration test device which can also be used for medium and high strength rocks. This device utilizes a low capacity loading device and special rod-like loading platen with a flat end. Aydan et al. (2008) also used Maruto's NP and compared the results obtained from both penetrometers and concluded that the device they developed may allow the determination of essential parameters such as UCS, tensile strength, friction angle and deformability properties from a single penetration test.

A modified Eijkelkamp hand penetrometer (Fig. 1, right) is also used in the Netherlands to estimate the strength of extremely to very weak limestones (Ngan-Tillard et al. 2011). The equipment is less sophisticated than Maruto's NP. The penetration force is read manually, when it has reached a steady state. The penetration depth is not recorded. In this study, the modified Eijkelkamp penetrometer is equipped with a $1 \mathrm{~mm}$ diameter, $8 \mathrm{~mm}$ long cylindrical needle having an apex angle of $60^{\circ}$ (resulting in a conical end height of $0.87 \mathrm{~mm}$ ). The Maruto needle is sharper. It is a rod of $0.84 \mathrm{~mm}$ diameter terminated by a truncated conical tip which decreases in diameter from 0.84 to $0.38 \mathrm{~mm}$ over about $5 \mathrm{~mm}$. The needle shape and size allow for easier penetration and affect the shape of the penetration force versus the penetration depth curve.

Normalized penetration curves recorded during insertion (and retrieval) of both needle types into very weak porous rocks, such as calcarenite and tuff, are shown in Fig. 2. A constant displacement rate was maintained by the use of a loading frame. Normalization of the penetration force and

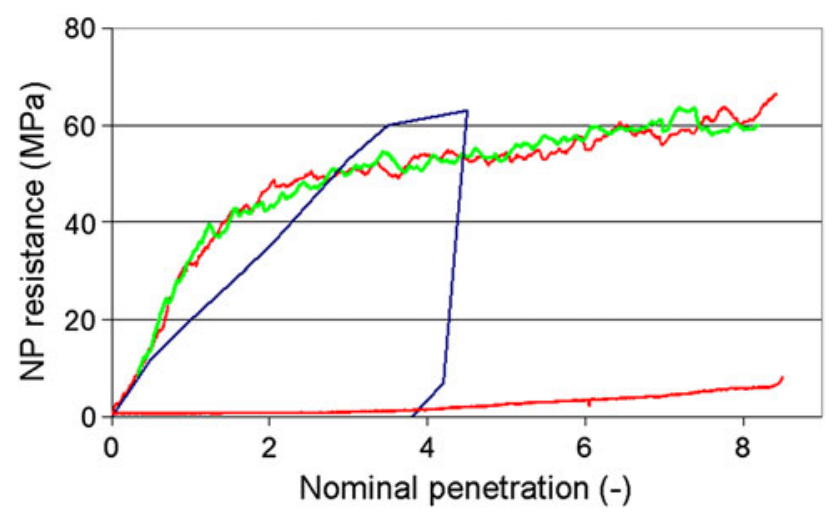

Fig. 2 Resistance to penetration and removal versus nominal penetration in calcarenite for the modified Eijkelkamp needle (red and green curves) and in tuff for the Maruto needle (dark blue curve). The curves are derived from Ngan-Tillard et al. (2011) and Aydan (2011) depth to penetration stress and nominal penetration strain was undertaken using the maximum needle diameter.

1. The resistance to penetration recorded with the modified Eijkelkamp increases with increasing penetration depth, first linearly up to 1.5 nominal penetration strain, then less sharply and non-linearly up to about 3 nominal strain before increasing again linearly at a lower gradient up to 8.5 nominal strain. After 3 nominal strain, both the cone and the cylindrical shaft of the needle have been pushed sufficiently into the rock that the cone tip and shaft resistance are fully mobilized. Thereafter, the penetration resistance continues to increase due to friction along the shaft. The friction resistance was measured during unloading. Its reduction as a function of nominal strain is almost linear.

2. The insertion of the Maruto needle produces a resistance to penetration curve with a constant gradient, at least up to 3 nominal penetration strain. Then, the curve becomes less steep, although a constant gradient was expected. The flatter curve could be due to a weakness zone within the tuff material. Observations similar to those reported in this section for the Maruto needle have been made by Sharp et al. (2009) when optimizing needle shape to minimize damage during in vivo needle penetration into brain tissues.

The tests made by Ulusay and Erguler (2011) using the Maruto needle suggest that for each rock type tested there is no difference between the NPR values determined at different penetration times, hence the rate of penetration has no effect on the NPR.

\section{Observational tools}

Four different observational tools were used to inspect the microstructural damage caused by NP: a Siemens medical CT scanner, a Phoenix Nanotem micro-CT scanner, a light microscope, and a Philips ESEM, at magnifications ranging from 50 to 500. The medical scanner images of dry cores of $3-5 \mathrm{~cm}$ diameter were recorded with a resolution of $0.5 \times 0.25 \times 0.25 \mathrm{~mm}^{3}$. For the calcarenite, the micro-CT scans were recorded on a $1.0 \mathrm{~cm}$ diameter core, before and after the NP test. For the other rocks, cylindrical fragments of material carved out manually from around the shaft opened by the needle, and scanned. A resolution ranging from 1.8 to $10 \mu \mathrm{m}$, depending on the sample size, was achieved in all directions. ESEM images were taken on fragments split manually, perpendicular to the hole opened by the NP. Observations with the light microscope were made on $30 \mu \mathrm{m}$ thick thin sections of tuff impregnated with araldite resin. Contrasts in mineral hardness as well as the 
presence of clayey minerals and powdery material around the needle shaft rendered the manufacturing of thin sections difficult.

\section{Tested rock materials}

A marl and a mudstone (representing fine grained rocks) and a tuff and a calcarenite (representing coarse grained rocks) were subjected to NP testing.

\section{Mudstone}

The mudstone originated from an open coal mine in western Turkey. X-ray diffraction analysis results suggest it consists of clay and mica minerals with some carbonate and rare quartz and feldspar (Erguler and Ulusay 2009). Its
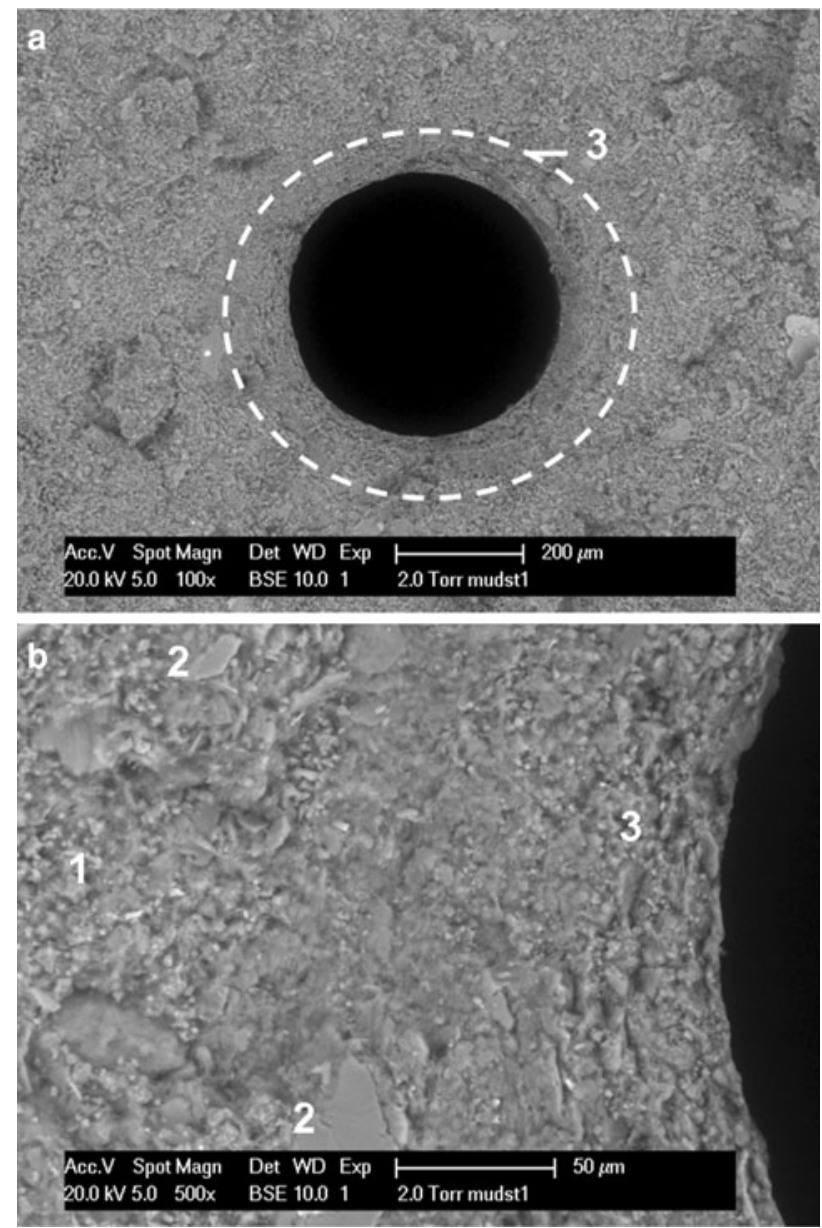

Fig. 3 ESEM photographs of a hole opened in the Mudstone with the Maruto needle. a At 100 magnification, b at 500 magnification. 1 platy and equidistant grains, 2 large platy grain, 3 zone affected by grain fracturation and re-orientation; the texture of zone 3 is different than that of the intact rock intact microstructure is displayed on the ESEM pictures in Fig. 3, away from the hole opened by the needle. Most of the grains are less than $5 \mu \mathrm{m}$ long. They are platy or equidimensional (label 1, Fig. 3b). Some platy grains (label 2, Fig. 3b) are 20-60 $\mu \mathrm{m}$ wide. The large plates tend to be parallel to the bedding planes. The grain packing is dense. The spread of more attenuating (white colour) and less attenuating (dark colour) minerals throughout the mudstone is visible on the micro-CT images (Fig. 4).
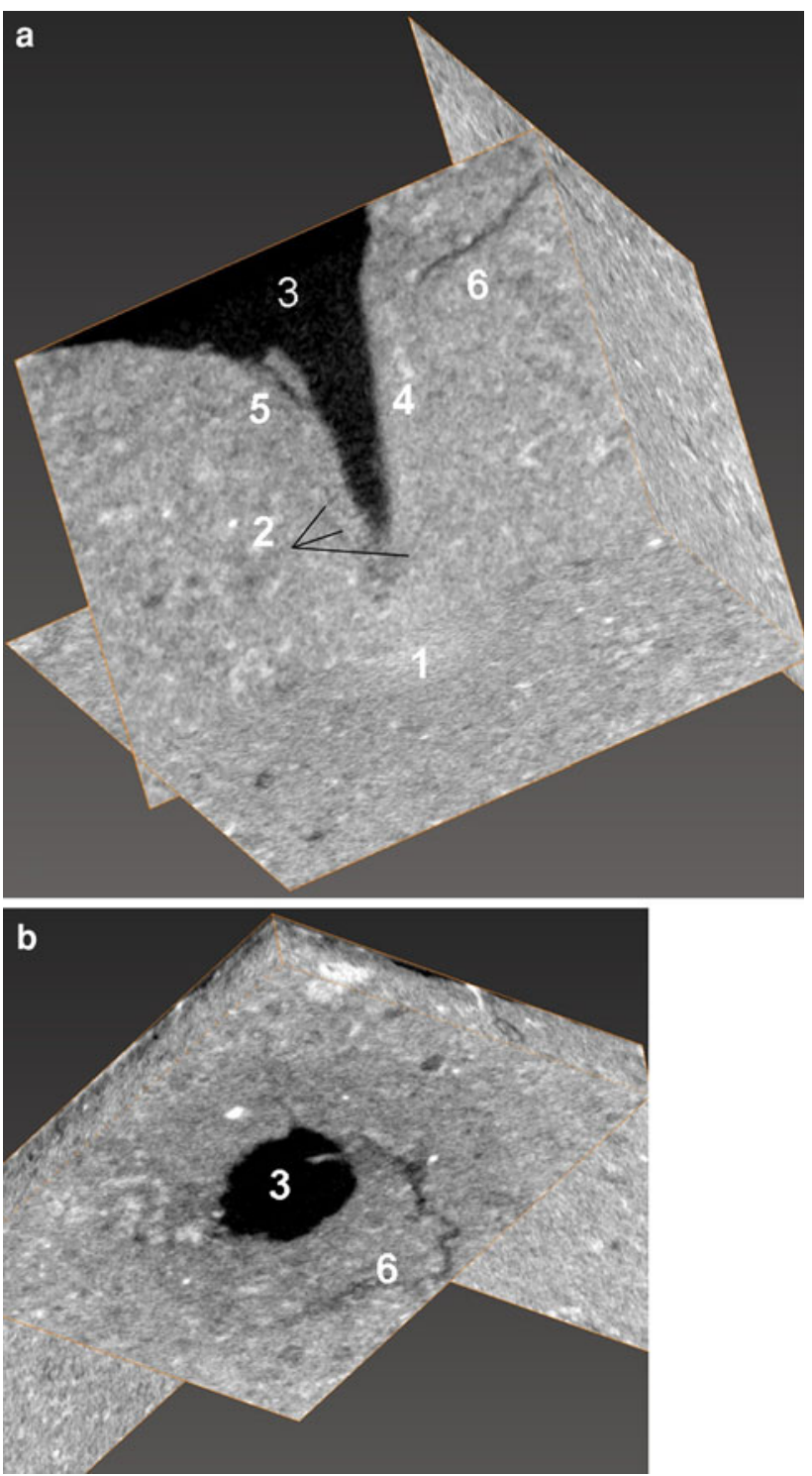

Fig. 4 Micro-CT images of a hole opened in the Mudstone with the Maruto needle. Resolution: $0.005 \times 0.005 \times 0.005 \mathrm{~mm}^{3}$ a damage overview in a section parallel to the needle shaft but not passing through its axis of symmetry, $\mathbf{b}$ detail of the crater development. 1 compacted zone ahead of the needle tip, 2 inclined dilatant crack, 3 crater, 4 compacted zone along the needle shaft, 5 flake deepening the crater, 6 chip widening the crater 
Fig. 5 ESEM photographs of holes opened in the Marl with the Maruto needle. a, c At 100 magnification; b, d at 500 magnification. 1 platy and equidistant grains, 2 tubular grain, 3 large platy grain, 4 pyrite, 5 and 8 zones affected by grain fracturation and reorientation, 6 and 9 spalling cracks, 7 coating. The texture of zones 5 and 8 near the hole is different from that of the intact rock

\section{Marl}

The marl also originated from an open coal mine in western Turkey and consists of clay and carbonate minerals with rare quartz, feldspar and mica (Erguler and Ulusay 2009). Its intact microstructure is displayed on the ESEM pictures of Fig. 5, away from the hole opened by the needle. Some of its grains have the size of clay and fine silt $(<5 \mu \mathrm{m})$. They are platy or equidimensional (label 1, Fig. 5b) or in some samples tubular (label 2, Fig. 5d). Others grains are platy and 15-30 $\mu \mathrm{m}$ wide (label 3, Fig. 5b). Pyrite concretions (framboids) are present (label 4, Fig. 5a, b). Bedding structures are visible on some of the micro-CT scans where the pyrite shows as bright spots (Fig. 6). The grain packing is dense.

\section{Calcarenite}

The calcarenite belongs to the Emael Member of the Maastricht Formation and was collected as a $0.4 \times 0.4 \times$ $0.5 \mathrm{~m}^{3}$ block from the Siebbegroeve mine near Maastricht, the Netherlands. Its grains are well sorted (Figs. 7, 8), predominantly well rounded and composed of fragments of marine organisms (bivalves, echinoids sponges, bryozoa, brachiopods, benthic foraminifera tests and peloids). Some millimetre to centimetre sized fossils lie parallel to the bedding. Intergranular pores occupy a variable but large volume. In addition, intraparticle porosity is present within the shell fragments (Fig. 8). The Emael calcarenite appears as a grain supported structure with no mud between the grains. Most grains are surrounded by a fringe of bladed or dog-teeth cement (Fig. 7). Cement overgrowth is such that the type of the bioclasts is difficult to recognise on the ESEM images (Fig. 7) although they are more obvious on the micro-CT images (Fig. 8) (Jagt 2008). The minerals of Emael calcarenite consist of more than $95 \%$ calcium carbonate. Spot EDEX measurements indicated a low-Mg calcite cement rim.

\section{Tuff}

The tuff originated from the Cappadocia region in central Turkey. The thin sections, ESEM pictures (Fig. 9) and micro-CT images (Fig. 10) suggest that the tuff specimens mainly consist of very small ash particles of amorphous material (glass) although some larger glass fragments are
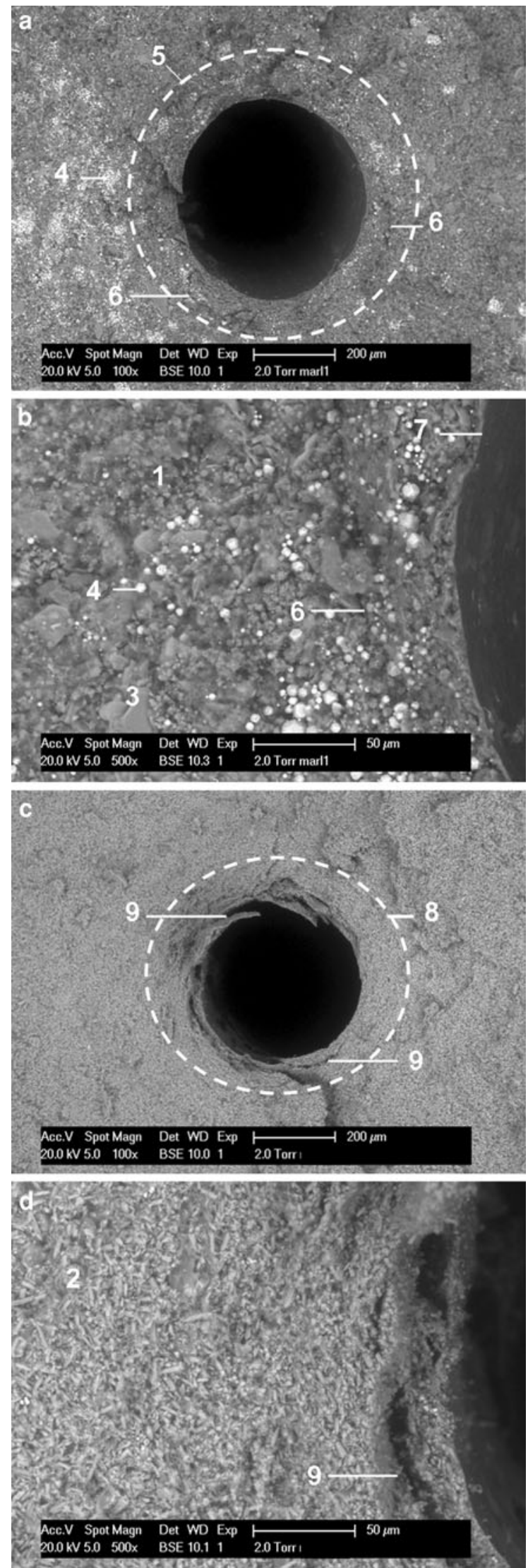

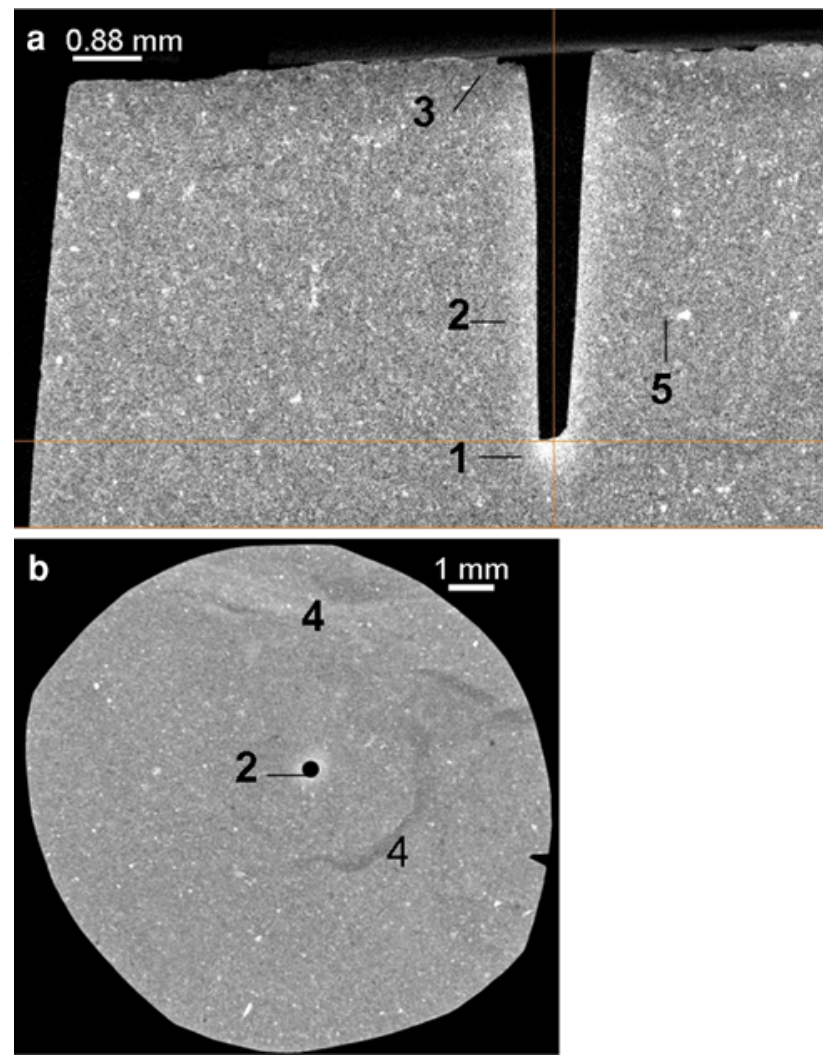

Fig. 6 Micro-CT images of a hole opened in the Marl with the Maruto needle. Section a parallel and $\mathbf{b}$ perpendicular to the shaft. 1 compacted zone ahead of the needle tip, 2 compacted zone along the needle shaft, 3 small crater, 4 bedding structures, 5 pyrite. Resolution: $0.0075 \times 0.0075 \times 0.0075 \mathrm{~mm}^{3}$

also present. The material also contains phenocrysts of quartz, plagioclase, alkali feldspar and biotite as well as some rock fragments made of fine grained volcanic rocks and pumice (label 1, Fig. 9d; label 3, Fig. 10a). The heterogeneity of the mineral composition and structure of the tuff is illustrated on the micro-CT scans in Fig. 10.

Physical properties and NPR and UCS values

An overview of some physical properties of the tested rocks, determined according to the methods suggested by ISRM (2007), is given in Table 1. According to previous investigations (e.g., Deere and Miller 1966; Bell 1978; Doberenier and DeFreitas 1986; Koncagul and Santi 1999), for a given rock type, the lower the unit weight, the lower the UCS. For the objectives of this research, rocks having low UCS values were required.

1. The unit weights of calcarenite, tuff, marl and mudstone samples selected for this research are low, ranging from 11.7 to $15.3 \mathrm{kN} / \mathrm{m}^{3}$.

2. The porosity of the calcarenite is high, varying between 40 and $52 \%$. It consists of a high

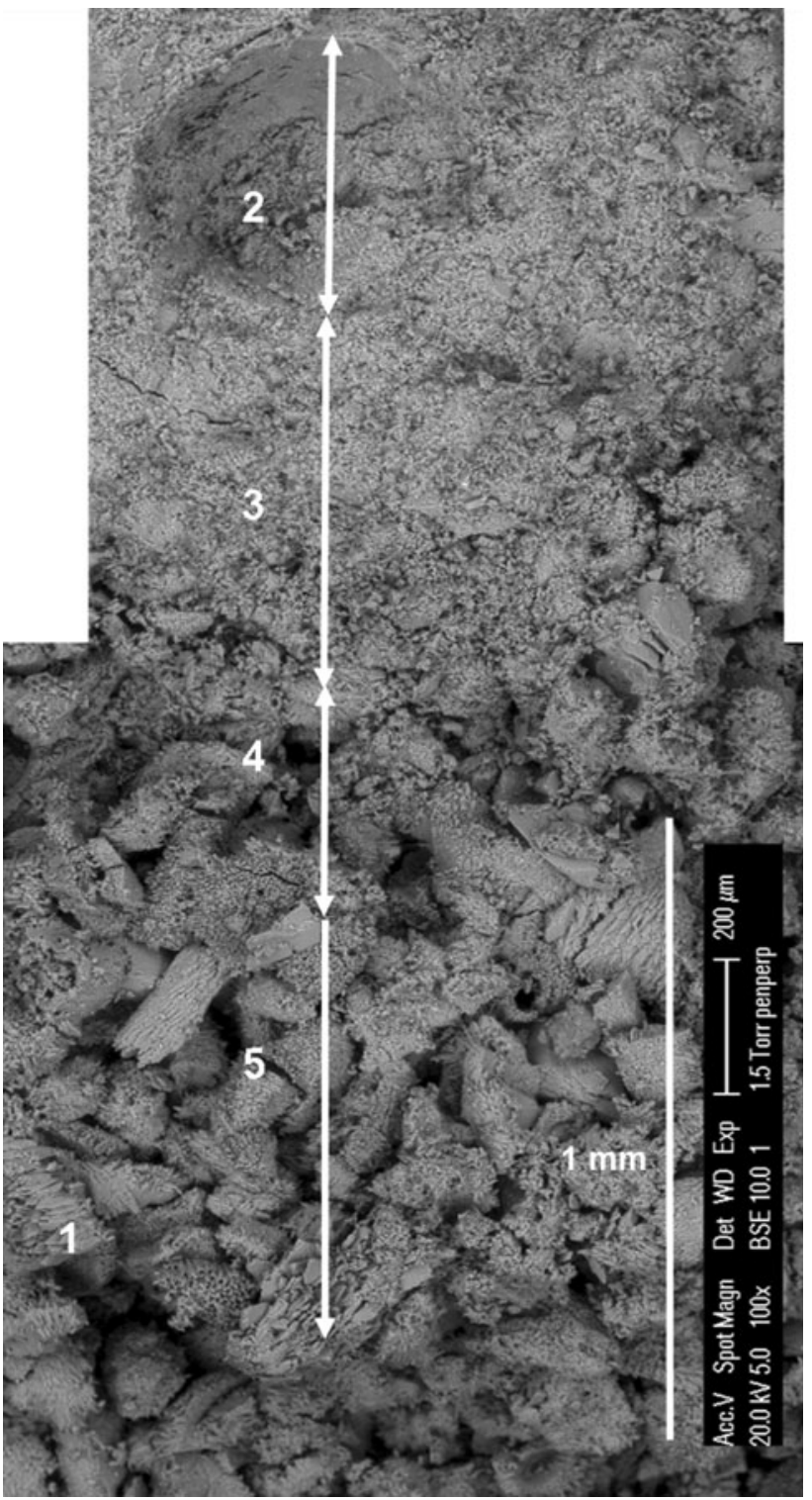

Fig. 7 ESEM photographs of the calcarenite near a hole opened with the modified Eijkelkamp needle at 100 magnification. 1 bioclast covered by a fringe of dog-teeth calcite cement, 2 imprint of needle tip, 3 crushed zone, 4 transition zone, 5 intact zone

interparticle porosity due to a high connectivity between cavities and of an intraparticle porosity present within the shell fragments and the foraminifera tests. Due to the presence of pumice, the tuff has the lowest porosities, varying between 26.4 and $33.6 \%$ while the mudstones have the highest porosities (43.4-47.6\%).

3. The calcarenite and the tuff are the weakest rocks, with a dry UCS varying between 2 and $7.45 \mathrm{MPa}$, while the marl and the mudstone are strongest with a UCS ranging from 4 to $16.1 \mathrm{MPa}$. Erguler and Ulusay (2009) showed that even small increases in water 

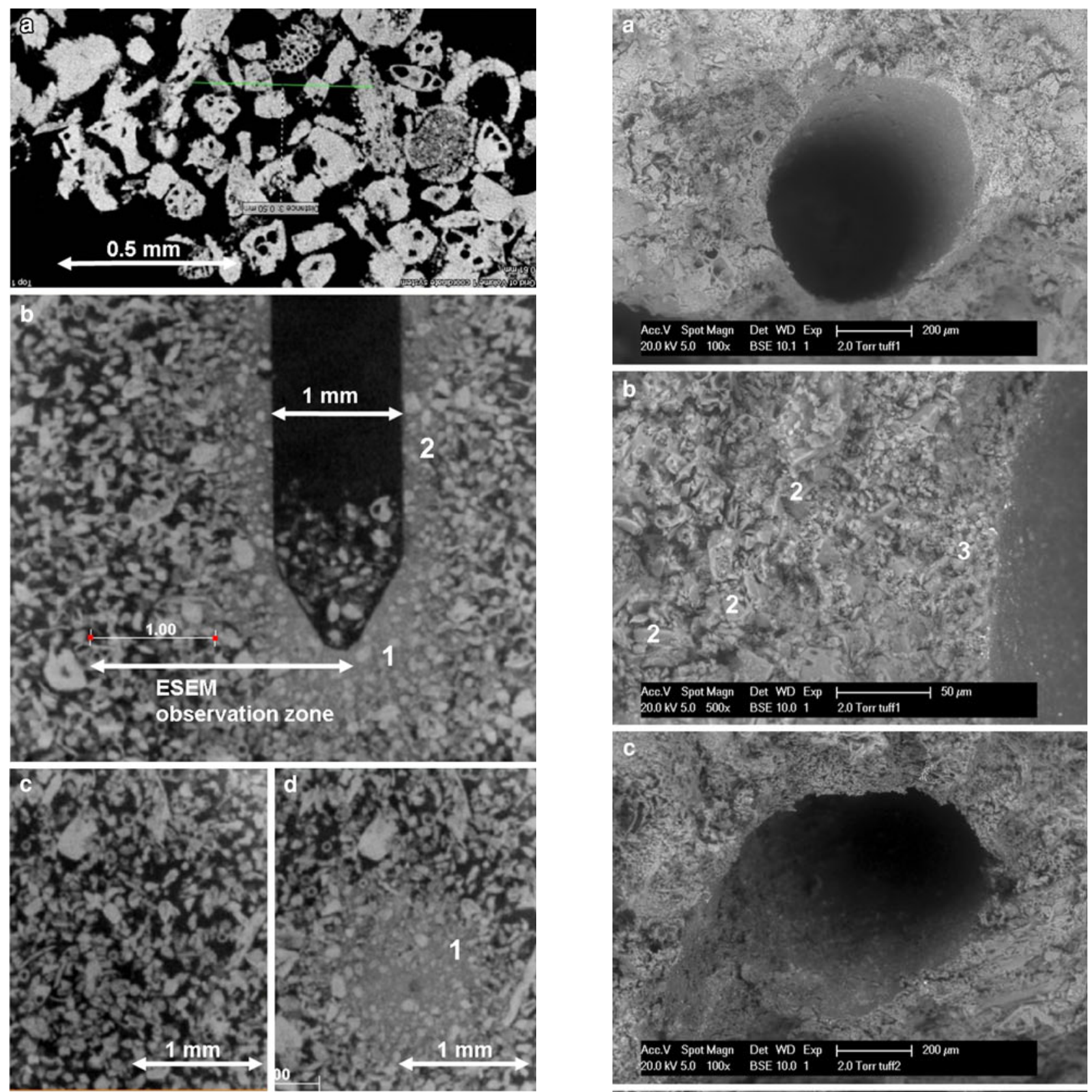

Fig. 8 Micro-CT images of the calcarenite. a Detail of the microstructure showing a large variety of bioclasts. Resolution: $0.0018 \mathrm{~mm}$. b-d Micro-CT scans before and after testing with the modified Eijkelkamp NP in a $10 \mathrm{~mm}$ diameter core. Resolution: $0.007 \times$ $0.007 \times 0.007 \mathrm{~mm}^{3}$. b Section parallel to needle shaft. Zone ahead of needle tip: $\mathbf{c}$ before and $\mathbf{d}$ after needle penetration and retrieval (note the extent of the zone observed with the ESEM). 1 and 2 crushed compacted zones. From Ngan-Tillard et al. (2011)

Fig. 9 ESEM photographs of holes opened in the tuff with the Maruto needle. a, c At 100 maginfication; b, d at 500 magnification. 1 pumice, 2 crystals of quartz, plagioclase, alkali feldspar or biotite, 3 zone affected by grain fragmentation. It is not clear when crushing of the pumice (1) occured

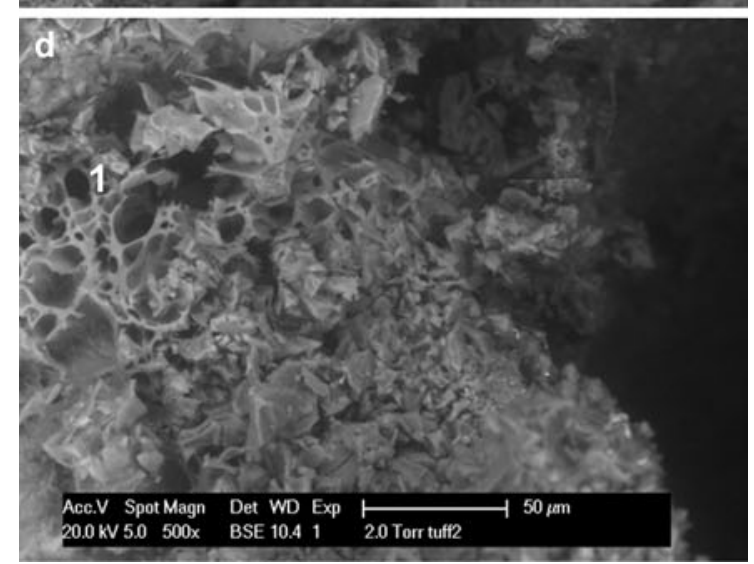



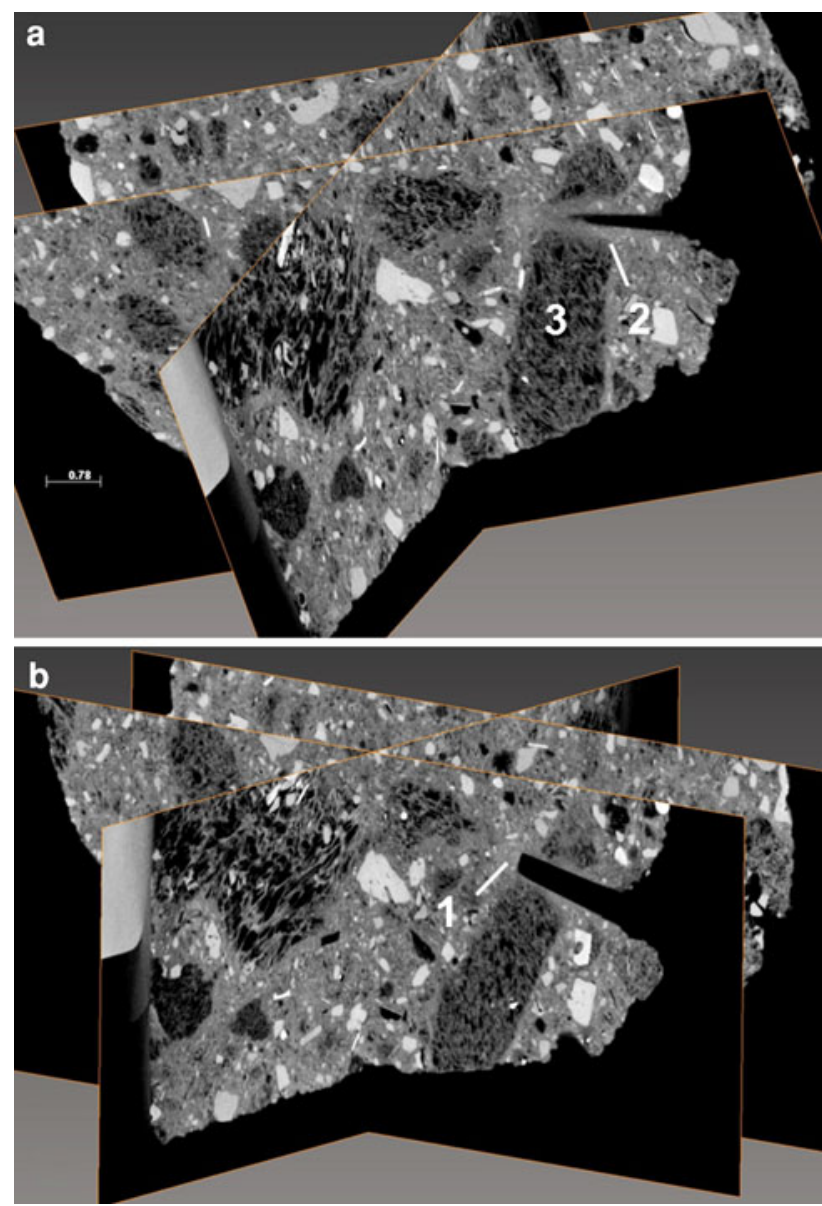

Fig. 10 Micro-CT images of a hole opened in the tuff with the Maruto needle showing. Resolution: $0.0075 \times 0.0075 \times 0.0075$ $\mathrm{mm}^{3}$. a View of the edge of the zone damaged by the needle, b cross-section through the central axis of the needle hole. 1 Compaction zone containing a half spherical discontinuity, 2 compacted zone along the needle shaft, 3 porous aggregate perforated by the needle

content cause a significant reduction in the UCS of these clay-bearing rocks. The tuff, mudstone and marl samples were tested by Maruto NP and their NPR values $\left(\mathrm{NPR}_{\mathrm{M}}\right)$ show a good agreement with UCS values (Table 1). The Eijkelkamp NP was used to test the calcarenite. The range of $\mathrm{NPR}_{\mathrm{E}}$ values is also given in Table 1.

\section{Damage caused by needle penetration testing}

Various holes were opened on different surfaces of small cores prepared from the tuff, marl and mudstone using the Maruto NP. Penetration refusal was observed when the modified Eijkelkamp was pushed into all the small cores tested with the Maruto penetrometer, except the tuff cores. The calcarenite was exclusively tested with the modified Eijkelkamp penetrometer. The observations made for the calcarenite are published in Ngan-Tillard et al. (2011) but are included here to facilitate the comparison of damage caused by the Maruto NP and in other rocks. The resolution of the CT scans was found to be insufficient to reveal any micro-structural changes apart from a densification around the needle and hence are not included in this paper. The preparation of surfaces by tensile splitting for ESEM observation generated micro-cracks that cannot always be discerned from micro-cracking caused by needle penetration.

\section{Mudstone}

As expected, the micro-scans of the mudstone specimen (Fig. 4) revealed a compaction zone around the needle (Fig. 4a, label 1) but also several sets of micro-cracks (Fig. 4a, label 2) and a crater (Fig. 4a, b, label 3) on the rock surface. The compaction zone is visible up to $0.4 \mathrm{~mm}$ ahead of the needle tip, but is less evident along the shaft (Fig. 4a, label 4). Around the shaft, a $0.1 \mathrm{~mm}$ thick ring of damaged material characterized by a different texture, grain fragmentation and grain re-orientation parallel to the shaft is perceptible on the ESEM pictures (Fig. 3, label 3). The sets of cracks appearing on the micro-CT scans are dilating and inclined. They start from the needle shaft and propagate towards the free surface of the sample. It is likely that the cracks were initiated by the sharp end of the needle, where stress concentration and gradient are high.

Table 1 Some physical properties, and NPR and UCS values of the tested rocks

\begin{tabular}{|c|c|c|c|c|c|}
\hline Rock type & Unit weight $\left(\mathrm{kN} / \mathrm{m}^{3}\right)$ & Porosity (\%) & UCS (MPa) & $\mathrm{NPR}_{\mathrm{M}}(\mathrm{N} / \mathrm{mm})$ & $\mathrm{NPR}_{\mathrm{E}}(\mathrm{MPa})$ \\
\hline Calcarenite & $12-15.5$ & $40.0-52.0$ & $2-7$ & & $25-65$ \\
\hline Tuff & $12.75-13.73$ & $26.41-33.61$ & $5.31-7.45$ & $27.47-30.03$ & \\
\hline Mudstone (samples 14-2-2 and 21-2) & $12.46-12.75$ & $43.43-47.58$ & $8.92-15.35$ & $20.41-25.21$ & \\
\hline Marl (samples 2 and 3) & $11.7-15.3$ & $44.10-47.97$ & $4.0-16.1$ & $17.9-35.6$ & \\
\hline
\end{tabular}

$N P R_{M}$ needle penetration resistance from Maruto NP, $N P R_{E}$ needle penetration resistance from Eijkelkamp NP 
The direction of the cracks is then dictated by the shearing along the needle shaft, resulting in a sort of rotation of the cracks. Relative shearing along the cracks concurrently causes dilation and further opening up of the cracks (Fig. 4a). At the location where the needle was pushed the cracks deepen the 1.1-1.6 mm wide (Fig. 4a, label 5), $0.4 \mathrm{~mm}$ deep crater (Fig. 4, label 3) observed during loading. The crater as well as the crack propagation is asymmetrical. The formation of new chips (Fig. 4, label 6) will make the crater $2.5-3.5 \mathrm{~mm}$ wide and more symmetrical. Compaction and shearing are thought to occur simultaneously with crack opening as the needle is forced into the material. However, as the micro-CT images were recorded after needle retrieval, the sequence of events is not known. The possibility that the inclined cracks were formed during needle removal, when tensile stresses develop during unloading, cannot be excluded.

\section{Marl}

In the marl (Fig. 6), the needle was pushed up to $4 \mathrm{~mm}$ deep, compared with only $2 \mathrm{~mm}$ in the mudstone. Material densification is observed on the micro-CT scans of the marl, both ahead of the needle tip (Fig. 6, label 1) and along its shaft (Fig. 6, label 2). Densification is highest ahead of the needle tip in a bulb-shaped zone with a height approximately equal to the smallest needle diameter $(0.38 \mathrm{~mm})$ (Fig. 6, label 1). No inclined dilating cracks propagating from the needle shaft nor spalling cracks around the needle can be discerned from the background noise of the micro-CT images near the shaft of the needle (Fig. 6). No large crater is observed at the core surface. Only a small chip (Fig. 6, label 3) has been ejected from the core surface. On the ESEM images of the marl (Fig. 5), grain fragmentation and re-orientation in a $0.075-0.1 \mathrm{~mm}$ thick zone encircling the shaft (labels 5 and 8) as well as spalling from the walls (label 6 and 9) are visible. In addition, a $0.003 \mathrm{~mm}$ thick coating (Fig. 5b, label 7) along the wall of the hole can be distinguished. Its origin has not been investigated. The spalling, i.e. the detachment of dinner shape plate slabs from the needle hole, is thought to have occurred during unloading when the high radial confining stresses generated by needle penetration were released.

\section{Calcarenite}

The micro-CT scans of the $1.0 \mathrm{~cm}$ diameter core recorded before and after NP (Fig. 8) as well as the ESEM pictures (Fig. 7) give a insight into the micro-structural damage at the grain scale (Ngan-Tillard et al. 2011). During needle penetration testing, up to $1 \mathrm{~mm}$ ahead of the needle tip the grains were crushed (Fig. 7, label 3, and Fig. 8c, d) and compacted in a zone that looks like an extension of the needle tip (Fig. 8b, label 1). As the modified Eijkelkamp needle was pushed forward, the clay-sized crushed material was further compacted in a $0.55 \mathrm{~mm}$ thick dense powdery zone surrounding the shaft of the needle and/or migrated into the pores of the adjacent intact material (label 2, Fig. $8 \mathrm{~b}$ ). The ratio of needle diameter over average grain size is less than 10 and the micro-structure of the calcarenite is non uniform at the grain scale. This partly explains the observed spreading of the needle penetration results. The fluctuations of the penetration depth-penetration force (Fig. 2) are attributed to the resistance or breakage of individual fossils. Final damage consists of crushing and compaction rather than de-bonding of grains. Crushing and compaction are also observed in compaction shear bands in triaxial testing under high confinement (Baxevanis et al. 2006). Under uniaxial loading conditions, cement connections and more rarely connections between cement fringes and grains are broken and grains remain intact (Molenaar and Venmans 1993). Despite this difference in damage type, resistance to NPR and UCS values are related.

\section{Tuff}

Changes in micro-structure are visible on the micro-CT images (Fig. 10) in proximity to the needle shaft. Figure 10a, b present zooms of the edge of the damaged zone in a tuff specimen and a cross-section through the central axis of the needle, respectively. They indicate that compaction occurs both ahead of the needle (Fig. 10b, label 1) and along the shaft (Fig. 10a, label 2). A dilating half spherical discontinuity having about the same diameter as the bottom of the hole can also be distinguished within the compacted zone ahead of the tip. However, it cannot be established when it has formed (during loading or unloading). Any dilating micro-cracks around the needle (apart from the half spherical discontinuity) have not been identified on the micro-CT images. The needle has been pushed through a dark porous aggregate (Fig. 10a, label 3) and destroyed the texture of the aggregate. Crushing has taken place and fines, not visible individually on the microCT scans, have been produced. The friability and variability of the (crushed) porous tuff render the interpretation and quantification of the ESEM pictures (Fig. 9) difficult. Despite this, it appears that grains in proximity to the needle hole have suffered from fragmentation (Fig. 9b, label 3).

Another $1 \mathrm{~mm}$ diameter hole was also opened on the same tuff specimen using the modified Eijkelkamp needle and scanned. The comparison between the damage caused by the Maruto and modified Eijkelkamp needles is illustrated in Fig. 11; both (a) and (b) images are at the same scale. The modified Eijkelkamp needle with its short 

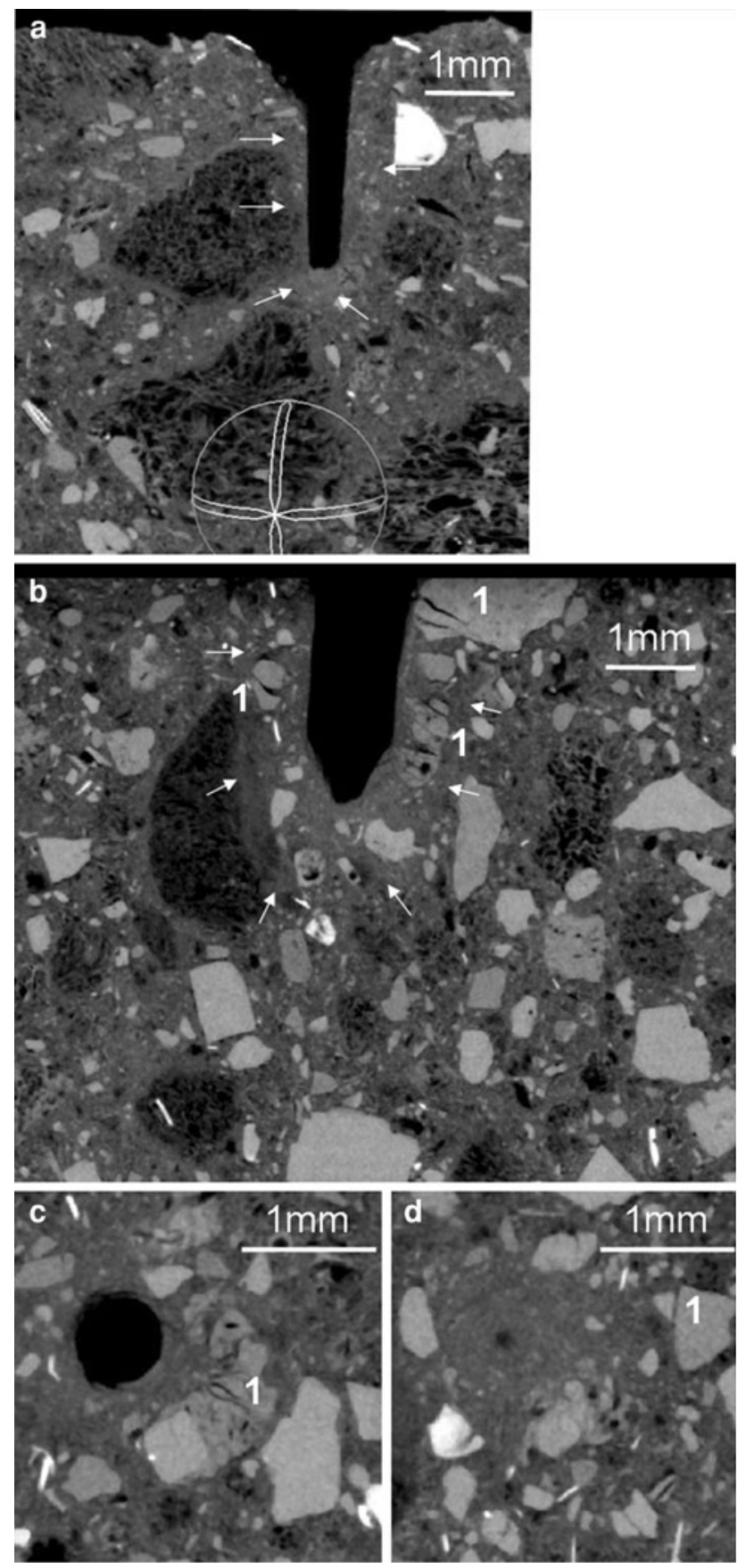

Fig. 11 Comparison of damage caused by the Maruto (a) and the modified Eijkelkamp (b-d) needles on Micro-CT scans. Resolution: $0.0075 \times 0.0075 \times 0.0075 \mathrm{~mm}^{3}$. a, b Cross sections parallel to the shaft, $\mathbf{c}$ cross-section perpendicular to the needle shaft, and $\mathbf{d}$ ahead of the needle tip. 1 Fractured grains. Arrows indicate extent of damage zone

conical head at the extremity of a $1 \mathrm{~mm}$ diameter rod had to fragment and open up strong aggregates (labels 1, Fig. $11 \mathrm{~b}, \mathrm{c})$ to penetrate into the tuff. During testing, a very high penetration resistance (above $300 \mathrm{MPa}$ ) was measured and the needle shaft buckled. However, as the diameter of the Maruto needle increases gradually from 0.38 to
$0.84 \mathrm{~mm}$ over several $\mathrm{mm}$, it might not have encountered any strong aggregates during penetration but gone through the weaker aggregates/cement/matrix by crushing them. Arrows highlight differences in the extent of the damaged zones. Nevertheless, it must be pointed out that microcracking does occur when Maruto's needle is pushed adjacent to or near harder mineral grains. Cracks propagating from the hole shaft towards and through a plagioclase are visible on photographs of a thin section (not shown here). A fractured grain of quartz situated along the shaft is also visible on the same thin section (not shown here). It is believed that the dilating cracks sub-parallel to the hole shaft (Fig. 11c) were formed during needle removal as high radial stresses caused by needle insertion were released.

\section{Discussion}

During needle penetration, very high compressive and shear stresses develop under the needle and stresses normal to the needle shaft increase. Based on the observations made on the micro-CT scans, it can be concluded that, in all the tested rocks, material densification occurs in a zone some 0.4 and $1 \mathrm{~mm}$ ahead of the Maruto and the modified Eijkelkamp needle, respectively. Densification around the shaft is most visible in the marl and the calcarenite. It extends up to about half a needle diameter from the shaft. In the fine grained rocks, the resolution of the micro-CT scans does not allow determination of whether compaction results from reorientation of clayey particles and/or crushing of clay aggregates or crushing of the carbonates for the marl.

The ESEM images reveal a $0.75-0.1 \mathrm{~mm}$ thick ring around the shaft where the material texture has changed and grain fragmentation and re-orientation are observed. In the mudstone, the most brittle of the tested materials, dilating cracks initiating at the needle tip and propagating towards the free surface, away from the needle shaft, are also visible. They deepen the large crater (about $2.5 \mathrm{~mm}$ diameter) observed at the point of impact on the core surface. In the marl, the crater is much less developed and dilating cracks cannot be discerned from the background noise. In the case of porous coarse-grained rocks, such as tuff and calcarenite, a punching through is observed. Crushing takes place and fine-grained materials (fines) are produced and compacted by the passage of the needle.

On one hand the mineralogy of the calcarenite is homogeneous, the size of its grains with respect to the needle diameter is large and both its inner-granular and inter-granular porosities are non-uniform. On the other hand, the tuff is made of various minerals and rocks. If its pumice is easily crushable, its grains made of quartz and 
plagioclase minerals are harder, and become fragmented rather than reduced to powder when they are close to the needle. Both situations confirm that the NP results in tuff and calcarenite are far more variable than in marl and mudstone. Analogous to cone penetration testing, scale effects are anticipated when the ratio of needle diameter to grain diameter is below 6-10.

When the Maruto and modified Eijkelkamp needles are compared, it is clear that in both cases the needle penetration induces very large plastic strains from the very beginning. Damage decreases with a decrease in the diameter of the needle and an increase in the slenderness of the needle. For the modified Eijkelkamp needle, the plastic response changes for a penetration depth; thereafter the needle diameter remains constant and the distance to the free surface is large enough. For the Maruto needle, the resistance to penetration increases linearly when the needle shaft (with its steadily increasing diameter) is pushed within the material. The tampered shaft of the Maruto needle allows for an easy insertion of the needle. Due to its smaller size and conical shape, it progresses within the material by generating less compaction and shearing than the modified Eijkelkamp needle. Because of its sharp tip, it cuts the material. The cutting force remains constant during penetration while the friction forces along the shaft increase as a function of penetration depth.

It is concluded that the Maruto needle, in comparison to the modified Eijkelkamp needle, has an optimized shape that reduces damage while maintaining the needle's resistance to buckling; an important feature where limited damage is required when testing, for example, the strength of archaeological material. During needle removal, a spalling process takes place around the needle shaft and contributes to the final damage. Less force is needed to push the Maruto needle, hence stronger material can be tested. The Eijkelkamp is less versatile. It is most effective in crushable material without hard inclusions while its larger diameter allows more representative strength results in porous coarse rocks.

As the NP test is a UCS strength test, it is interesting to compare the failure patterns observed during needle penetration testing to those published in the literature for the four types of rock tested. In the calcarenite and tuff, final damage consists of crushing and compaction rather than de-bonding of grains. The former is observed in compaction shear bands in triaxial testing under high confinement while the latter is observed in UCS conditions. In the fine grained rocks, such as mudstone and marl, compaction is more pronounced in the final damage. Typical shear failure is observed during the failure of these fine grained rocks under uniaxial and triaxial loading conditions. Despite differences in damage type, resistance to needle penetration and UCS values are significantly related (Okada et al.
1985; Yamaguchi et al. 1997; Takahashi et al. 1998; Naoto et al. 2004; Erguler and Ulusay 2007 and 2009; Ulusay and Erguler 2011).

\section{Conclusions}

The four types of rock tested present differences in failure patterns observed after needle penetration testing. All failure patterns are concentrated around the needle shaft and for all the rocks they consist of a compaction zone ahead and along the needle shaft.

In the case of coarse-grained rocks such as calcarenite and tuff, crushing takes place and fines are produced. When the diameter of the needle increases (Eijkelkamp needle) the grains are crushed and compacted in a zone up to a $1 \mathrm{~mm}$ ahead of the needle tip which looks like an extension of the needle tip.

When the Maruto and Eijkelkamp needles are compared, the damage caused by the needle decreases with a decrease in the diameter of the needle and an increase in the slenderness of the needle. Dilating cracks that initiate from the needle shaft and propagate sideway up to the free rock surface have been observed in the micro-CT scans of the mudstone. They are thought to cause and deepen the crater seen around the impact of the needle. In the tuff, thin micro-cracks are also visible. However, their extent is confined to the proximity of the needle.

The post-mortem observations do not allow the sequence of the different failure mechanisms taking place to be established. However, the spalling damage is thought to have occurred during needle retrieval. The spread of NPR values reflects either a low needle diameter to mean grain size, an uneven pore space distribution, or a mixture of crushable and less easily crushed grains.

The observations presented in this study provide a better understanding of the failure mechanisms taking place during NP testing. They can support the derivation of a theoretical expression of the UCS as a function of the insertion and retrieval stresses. Modelling needle penetration in the framework of the spherical cavity expansion theory seems to be pertinent for the marl, the calcarenite and the tuff, provided a proper rock model is used that captures, for example, the rock cohesive strength and its sensitivity to crushing. For the brittle mudstone, fracture mechanics should be added to model the material cutting by the sharp needle tip.

As plastification occurs from the start of the test, it is unlikely that elastic parameters can be derived from NP testing.

The observations made can be used to validate constitutive models based on micro-mechanics, along non-trivial stress paths. 
Acknowledgments The authors thank to Maaike van Tooren and Arjan Thijssen for the interpretation of the thin sections, and respectively, the ESEM photographs.

Open Access This article is distributed under the terms of the Creative Commons Attribution License which permits any use, distribution, and reproduction in any medium, provided the original author(s) and the source are credited.

\section{References}

Aydan Ö (2011) Personal communication on Maruto normalized penetration curve. Tokai University, Shizuoka

Aydan Ö, Watanabe S, Tokashiki N (2008) The inference of mechanical properties of rocks from penetration tests. Proceedings of 5th Asian Rock Mechanics Symposium (ARMS'5), vol 1, 24-26 November 2008 Tehran, Iran, pp 213-220

Baxevanis T, Papamichos E, Flornes O, Larsen I (2006) Compaction bands and induced permeability reduction in Tuffeau de Maastricht calcarenite. Acta Geotech 1:123-135

Bell FG (1978) The physical and mechanical properties of the Fell Sandstones, Northumberland, England. Eng Geol 12:1-29

Deere DU, Miller RP (1966) Engineering classification and index properties for intact rock. Department of Civil Engineering, University of Illinois, Urbana, IL, pp 90-101

Doberenier L, DeFreitas MH (1986) Geotechnical properties of weak sandstones. Geotechnique 36:79-94

Erguler ZA, Ulusay R (2007) Estimation of uniaxial compressive strength of clay-bearing weak rocks using needle penetration resistance. Proceedings of the 11th ISRM Congress, Lisbon, Portugal, vol 2, pp 265-268

Erguler ZA, Ulusay R (2009) Water-induced variations in mechanical properties of clay-bearing rocks. Int J Rock Mech Min Sci 46:355-370

Hachinohe S, Hiraki N, Takasuke S (1999) Rates of weathering and temporal changes in strength of bedrock of marine terraces in Boso Peninsula, Japan. Eng Geol 55:29-43

ISRM (2007) The Complete ISRM Suggested methods for rock characterization, testing and monitoring: 1974-2006. In: Ulusay R, Hudson JA (eds) Suggested methods prepared by the commission on testing methods, International Society for Rock Mechanics, Compilation Arranged by the ISRM Turkish National Group, Kozan Ofset, Ankara, Turkey
Jagt J (2008) Identification of bioclasts on ESEM and micro-CT images. Personal communication, Maastricht Natural History Museum, The Netherlands

Japan Society of Civil Engineers (JSCE) (1991) Proposed testing methods for soft rock. Tokyo, Committee on Rock Mechanics of JSCE 1991 (in Japanese)

Japanese Geotechnical Society (JGS) (2004) Method for engineering classification of rock mass (JGS: 3811-2004). JGS Publication, Tokyo, pp 1-6

Koncagul EC, Santi PM (1999) Predicting the unconfined compressive strength of the Breathitt shale using slake durability, shore hardness and rock structural properties. Int J Rock Mech Min Sci $36: 139-153$

Maruto Co. Ltd (2006) Penetrometer for soft rock: model SH-70 instruction manual, Tokyo

Molenaar N, Venmans AAM (1993) Calcium carbonate cementation of sand: a method for producing artificially cemented samples for geotechnical testing and a comparison with natural cementation processes. Eng Geol 35:103-122

Naoto U, Yoshitake E, Hidehiro O, Norihiko M (2004) Strength evaluation of deep mixing soil-cement by needle penetration test. J Jp Soc Soil Mech Found Eng 52(7):23-25 (in Japanese)

Ngan-Tillard DJM, Verwaal W, Mulder A, Engin HK, Ulusay R (2011) Application of the needle penetration test to a calcarenite, Maastricht, The Netherlands. Eng Geol 123:214-224

Okada S, Izumiya Y, Iizuka Y, Horiuchi S (1985) The estimation of soft rock strength around a tunnel by needle penetration test. J Jpn Soc Soil Mech Found Eng 33(2):35-38 (in Japanese)

Sharp AA, Ortega AM, Restrepo D, Curran-Everett D, Gall K (2009) In vivo penetration mechanics and mechanical properties of mouse brain tissue at micrometer scales. IEEE Trans Biomed Eng 56(1):45-53

Takahashi K, Noto K, Yokokawa I (1998) Strength characteristics of Kobe Formation in Akashi Strata (No.1). Proceedings of 10th Japan National Conference on Geotechnical Engineering, The Japanese Geotechnical Society, pp 1231-1232 (in Japanese)

Ulusay R, Erguler ZA (2011) Investigation of the performance of the needle penetration test and its use in rock engineering. Kulaksiz S, Tuncay E (eds) Proceedings of ROCKMEC'2011: Xth regional rock mechanics Symposium, Ankara, Turkey, pp 171-178 (in Turkish)

Yamaguchi Y, Ogawa N, Kawasaki M, Nakamura A (1997) Evaluation of seepage failure resistance potential of dam foundation with simplified tests. J Jpn Soc Eng Geol 38(3): $130-144$ 